\title{
Design and Implementation of Wearable Microstrip Fabric Antenna for RF Energy Harvesting
}

T. Rubesh kumar ( $\nabla$ rubeshkumar.id@gmail.com )

Anna University Chennai https://orcid.org/0000-0002-6348-3981

Moorthi Madhavan

Saveetha University Saveetha Engineering College

\section{Research Article}

Keywords: 5G, Fabric Antenna, Microstrip, RF Energy, Omnidirectional

Posted Date: March 22nd, 2021

DOI: https://doi.org/10.21203/rs.3.rs-323258/v1

License: (c) (i) This work is licensed under a Creative Commons Attribution 4.0 International License. Read Full License 


\section{Abstract}

In $5 \mathrm{G}$ network, the key parts are millimeter wave band (mmWave band) involving $26 \mathrm{GHz} \& 28 \mathrm{GHz}$ which aims to solve issues related to traffic using its wide bandwidth. Features of $5 \mathrm{G}$ such as transmitters with high directivity, wide bandwidth and base station with high density project it as a promising source of RF energy harvesting. In order to harvest RF power from the full spectrum in an efficient way, broadband antenna design is demanded. This paper focuses on designing wearable microstrip fabric antenna operating in $5 \mathrm{G}$ spectrum at $26 \mathrm{GHz} \& 28 \mathrm{GHz}$ for RF energy harvesting. Impedance bandwidth of the antenna is about $20 \mathrm{GHz}$ to $30 \mathrm{GHz}$ exhibiting omnidirectional pattern of radiation with on-body gain with a peak value of $7 \mathrm{~dB}$ making it suitable for harvesting RF energy. On body radiation efficiency \& off body radiation efficiency are obtained as $40 \%$ and $60 \%$ when operating in the frequency range of $24 \mathrm{GHz} \& 30$ $\mathrm{GHz}$. In mmWave band, dielectric characterization of a two line fabric substrate microstrip antenna is obtained. Fabrication of the antenna is done using polyimide copper laminates etched with ultra thin size $150 \mu \mathrm{m}$ on a woven polyester substrate of $310 \mu \mathrm{m}$ thickness. Improved gain and stable bandwidth are achieved from the proposed antenna design when demonstrated in human proximity providing high robustness.

\section{Introduction}

In the future $5 \mathrm{G}$ cellular networks, a major part is represented by the millimeter wave band which provides broad spectrum for mitigating issues related to traffic limitations present in the conventional mobile networks. Basic features of $5 \mathrm{G}$ networks are smaller base stations with high density and broad spectrum [1-3]. In frequency range of mmWave, wave absorption by water, air occurs resulting in reduction in their ability for obstacle penetration. Higher losses of propagation in these frequency bands can be overcome significantly by the process of beam forming and designing phased antenna arrays with high directionality. Low power devices can be powered by harvesting RF energy available from these antennas. This energy harvesting method is popular as it enables low power devices for battery less operation [46 6). These $5 \mathrm{G}$ networks are attractive source of radio frequency energy as the transmitting antennas are large arrays with densely located base stations providing improved coverage of energy. Additionally the mmWave frequency band is efficient compared to the currently existing sub $6 \mathrm{GHz}$ mobile cellular networks [7].

In addition to RFEH (Radio Frequency Energy Harvesting), SWIPT (Simultaneous Wireless Information and Power Transfer) and WPT (Wireless Power Transfer) can coexist in mmWave band in 5G networks as the spectrum is significantly broad. The key component in an WPT or RFEH system is rectifying antennas also termed as rectennas along with a SIW (Substrate Integrated Waveguide) rectenna is utilized for ISM (Industrial Scientific Medical) band operating at $24 \mathrm{GHz}$, for generating DC output voltage of 0.6 Volt from an incident mmWave of power $10 \mathrm{~mW}$ [8-11]. Fabrication of an antenna array operating at $60 \mathrm{GHz}$ is done using copper foil ablated on a substrate of polyester cotton with $40 \%$ radiation efficiency for body centric communication. Woven rigid threads are utilized for textile antennas operating at SIW 5G spectrums. 
In this paper, a fabric based antenna is designed, whose fabrication is done using polyimide copper laminates etched for optimized performance of energy harvesting on-body operating at licensed band of $5 \mathrm{G}$ network at $26 \mathrm{GHz} \& 28 \mathrm{GHz}$. The proposed textile antenna has ultra wide band design able to cover the full $\mathrm{mmWave} \mathrm{licensed} \mathrm{spectrum} \mathrm{of} 5 \mathrm{G}$ network. This approach is a novel design able to provide increased on-body antenna gain. Radiation efficiency and higher gain are achieved from the proposed antenna than conventional microstrip mmWave frequency antennas.

\section{Proposed Antenna's Design \& Fabrication}

The proposed antenna design is based on Vivaldi antipodal type antenna of ultra wide band provided with a circular curve at the end for bandwidth improvement. The main goal of antenna design is to maximize radiation efficiency with minimal radiator size. Radiating elements are larger in size such as patches in antennas exhibits higher dielectric losses resulting in reduced radiation efficiency [12-15]. The proposed antenna with its dimensions is as shown in Fig. 1 where on both sides asymmetrical antipodal alignment is viewed.

The Fabrication of the proposed textile antenna requires etched copper laminates, copper foils, adhered conductive or woven textile on which screen \& inkjet printing has to be done. Manufacturing imperfections are minimized by the process of high resolution which produces homogeneous smooth conductor for the mmWave antennas which is generally lesser than $1 \mathrm{~mm}$. As the thickness of the interface layer required in conductor printing is higher, it has been excluded as it results to high dielectric losses thereby reducing efficiency of the antenna [16].

Improvement in flexibity is provided by Polyimide ultra-thin copper laminates in comparison with copperfoils with reduced thickness in comparison with printed interface-layers thereby reducing dielectric losses [17-20]. A standard process of photolithography is used for fabricating copper laminates by plotting the track pattern on a mask of dark film [21]. The standard equipment of PCB manufacturing is used to achieve a minimal feature size of $150 \mu \mathrm{m}$. The fabrication process of the proposed antenna is as shown in Fig. 2 (a-g).

Even though characterization of textile substrate is at $2.45 \mathrm{GHz}$, due to textile in homogeneity there is necessity of two line characterization to be performed for the proposed antenna. Hence two microstrip lines are built, each with $50 \Omega$ impedances. Measurement of insertion loss (S21) is done for a $30 \mathrm{~mm}$ microstrip and $50 \mathrm{~mm}$ microstrip fabricated on a polyester woven substrate of thickness $310 \mu \mathrm{m}$ as shown in Fig. 3. Extracted lines represented in graph exclude the losses due of impedance match introduced due to inclusion of test connector. Dielectric constant of the total fabricated antenna is computed as 1.64 , with insertion loss measured as $0.90 \mathrm{~dB} / \mathrm{cm}$ at a frequency of $28 \mathrm{GHz}$ and $1.79 \mathrm{~dB} / \mathrm{cm}$ at a frequency of $60 \mathrm{GHz}$ which is only $0.11 \mathrm{~dB} / \mathrm{cm}$ greater than existing antenna system at $60 \mathrm{GHz}$ due to the thick textile material utilized in the proposed antenna. Higher insertion loss is obtained in the frequency range of $15 \mathrm{GHz}$ and $30 \mathrm{GHz}$ as the reflection at VNA-connector based plane is due to flexibility $\&$ thickness of the textile substrate. 


\section{Proposed Antenna Simulation \& Measurement 3.1 Full Wave Antenna Simulation}

The design and simulation of 3D model of proposed antenna is performed using CST Microwave Studio software. The Simulation of 3D antenna model is done along with $1 \mathrm{~mm}$ human skin of CST's Voxel. Penetration of mmWaves of $5 \mathrm{G}$ network does not penetrate much past the layer of human skin hence antenna model includes human skin layer for simplifying it. 3D model of antenna excited by a waveguide port of $50 \mathrm{ohm}$ is as shown in Fig. 4. A test connector of $1.85 \mathrm{~mm}$ is included, whose 3D model is simulated for analyzing the variations induced due to connector in the measurement of return loss S11 and for correcting \& de-embedding the $S$ parameters measured from the antenna. The simulation is done without the connector, where the return loss exhibiting at a bandwidth of $9.5 \mathrm{GHz}$ is as shown in Fig. 5 . The S11 parameter represents the amount of power radiated by the antenna describing the antenna's reflection coefficient [22-24]. This parameter S11 must be lesser than - $10 \mathrm{~dB}$ for the antenna to radiate efficiently. The $\mathrm{S} 11$ parameter for the proposed antenna design is lesser than $-10 \mathrm{~dB}$ as shown by the Fig. 5 hence can radiate efficiently thereby making it suitable for radio frequency energy harvesting technique.

\subsection{Antenna's Parameter Measurement}

Testing of antenna under test is done using a E8361A67 GHz PNA network analyzer. The antenna under test (AUT) is terminated with $1.85 \mathrm{~mm}$ solder edge connector. The return loss of AUT is both measured and simulated involving the connector exhibiting good agreement in the frequency range, as shown in Fig. 5 validating through simulation. Additional reflection due to the connector is corrected by the 3D model as represented by the measurement of $S$ parameter of the antenna. There is no difference in the measurement value of S11 both on-body \& off-body both with bending \& without bending. Simulation of radiation pattern using CST in far field is monitored at the frequency of $26 \mathrm{GHz} \& 28 \mathrm{GHz}$ where excitation is done using a $50 \Omega$ discrete port. Gain of the AUT is measured both during transmission and reception, where path loss is computed using Friis model [25-27]. The simulated antenna gain with its efficiency and measured realized gain are represented in Table 1. 
Table 1

Proposed Antenna Simulated \& Measured Parameters

\begin{tabular}{|llll|}
\hline Frequency Range & $\begin{array}{l}\text { Simulated } \\
\text { Gain }\end{array}$ & $\begin{array}{l}\text { Measured Realized } \\
\text { Gain }\end{array}$ & $\begin{array}{l}\text { Simulated Radiation } \\
\text { Efficiency }\end{array}$ \\
\hline $\begin{array}{l}26 \mathrm{GHz} \text { RF signal on- } \\
\text { Space }\end{array}$ & 5.39 & - & $77.01 \%$ \\
\hline $\begin{array}{l}26 \mathrm{GHz} \text { RF signal on- } \\
\text { Body }\end{array}$ & 6.19 & - & $48.99 \%$ \\
\hline $\begin{array}{l}28 \mathrm{GHz} \text { RF signal on- } \\
\text { Space }\end{array}$ & 5.48 & 5.31 & $76.98 \%$ \\
$\begin{array}{l}28 \mathrm{GHz} \text { RF signal on- } \\
\text { Body }\end{array}$ & 7.12 & 6.70 & $54.10 \%$ \\
\hline
\end{tabular}

The gain of the antenna is the key number representing the performance of the antenna combining the electrical efficiency and directivity of the antenna. In $5 \mathrm{G}$ frequency band, any antenna can provide satisfactory performance only if the gain of the proposed antenna ranges between $6 \mathrm{~dB}$ to $9 \mathrm{~dB}$ gain values. From the Table I it is clear that the textile antenna on body is able to perform satisfactorily as the gain lies within the stipulated range. Hence it proves that the proposed antenna design is able to harvest RF energy in wearable textile. The Simulation of Cartesian plot both in E plane and $\mathrm{H}$ plane along with 3D gain plots for the proposed antenna is done both on skin and off skin at the frequency range of $28 \mathrm{GHz}$ is as shown in Fig. 6.

Two dimensional radiation plots is as shown in Fig. 7 using elevation angle and gain by considering two frequencies in the operating range of $5 \mathrm{G}$ network. Efficiency of the proposed antenna depends on its directivity and gain [28] hence the proposed antenna is able to provide satisfactory gain for RF energy harvesting application.

\subsection{Measurement of Effects of Human Proximity}

The proposed textile antenna operating in $5 \mathrm{G}$ frequency band experiences on skin additional capacitance as the dielectric constant of the skin is higher than that of air. This is indicated by the antenna impedance with high capacitive component as shown by Smith chart in Fig. 7(b). This additional capacitance due to antenna in the human proximity can be reduced by placing asymmetric antipodal arms which reduces the parallel plate capacitance in the antenna. This asymmetrically placed antipodal arm reduces the imaginary component by $50 \%$ at a operating frequency of $26 \mathrm{GHz}$ without the requirement of any change or modification required in antenna design. An impedance bandwidth for the configuration described for the antenna is achieved in the range of $20 \mathrm{GHz}$ to $30 \mathrm{GHz}$ when placed on-body.

Return loss of proposed antenna is represented in Fig. 7 (a) both with symmetric antipodal arms and asymmetric antipodal arms. The conventional symmetric antipodal arms provide reduced bandwidth with unstable imaginary impedance as shown by Fig. 7 (b). But these effects due to human proximity are overcome by introducing the proposed asymmetrical antipodal arms which is able to provide improved bandwidth as well as provide stable imaginary impedance as shown in Smith chart above. The antenna 
arms when placed asymmetrically, it in turn provides more exposure to the skin underneath the antenna. This type of placement may reduce the antenna shielding as expected but the proposed antenna is able to provide higher gain compared to that of patch antennas with solid ground planes. This is due to the reason that the incident ray is reflected more as well as radiated more with mmWaves in $5 \mathrm{G}$ band off the surface of the skin in the operating frequency range. At the frequency of $26 \mathrm{GHz}$, a gain improvement of 1 $\mathrm{dB}$ is achieved with the improvement in peak efficiency of $5 \%$. Peak gain when placed on-skin with its radiation efficiency in the bandwidth of proposed antenna is as shown in Fig. 8 which is comparatively higher than that of existing textile antenna. These results make the proposed textile antenna more suitable for RF energy harvesting technique from $5 \mathrm{G}$ network.

\section{Conclusion}

This paper has presented the novel design of textile antenna which is able to operate at the frequency range of $5 \mathrm{G}$ network specifically in mmWave band of $26 \mathrm{GHz} \& 28 \mathrm{GHz}$ providing improved bandwidth and gain on-body. Hence this two line microstrip antenna design is much suitable for RF energy harvesting application. The fabrication process is simpler utilizing standard materials available commercially for the fabrication process of the proposed textile antenna. Wearable rectennas with mmWave radiation enables higher efficiency of reception in the process of energy harvesting. The negative effects of human proximity are overcome by asymmetrical placement of antenna arms hence providing improved bandwidth and gain than the convention textile antenna systems. This low cost antenna design is capable of powering low power devices without the requirement of batteries or any hassle of recharging them. Future work involves designing matching network for the rectifier in microstrip textile antenna and further investigation for reduction of induced losses in the mmWave band of $5 \mathrm{G}$ network.

\section{Declarations}

\section{Compliance with Ethical Standards}

\section{Conflict of interest}

The authors declare that they have no conflict of interest.

\section{Human and Animal Rights}

This article does not contain any studies with human or animal subjects performed by any of the authors.

\section{Informed Consent}

Informed consent was obtained from all individual participants included in the study.

Funding: Not applicable 
Conflicts of interest Statement: Not applicable

\section{Ethics approval:}

Consent to participate: Not applicable

Consent for publication: Not applicable

\section{Availability of data and material:}

Data sharing is not applicable to this article as no new data were created or analyzed in this study.

Code availability: Not applicable

\section{Authors' contributions}

TRK agreed on the content of the study. TRK and MM collected all the data for analysis. TRK agreed on the methodology. TRK and MM completed the analysis based on agreed steps. Results and conclusions are discussed and written together. Both author read and approved the final manuscript.

\section{References}

1. Apsite I, Biswas A, Li Y, lonov L Microfabrication Using Shape-Transforming Soft Materials. Adv. Funct. Mater. 2020, 30

2. Yang K, Isaia B, Brown LJE, Beeby S (2019) E-Textiles for Healthy Ageing. Sensors 19:4463

3. Moraru A, Ursachi C, Helerea EA, New Washable (2020) UHF RFID Tag: Design, Fabrication, and Assessment. Sensors 20:3451

4. Imran D et al., "Millimeter wave microstrip patch antenna for $5 \mathrm{G}$ mobile communication," 2018 International Conference on Engineering and Technologies E (ICEET), Lahore, 2018, pp.1-6

5. Sunthari PM, Veeramani R, "Multiband microstrip patch antenna for $5 \mathrm{G}$ wireless applications using MIMO techniques," 2017 First International Conference on Recent Advances in Aerospace Engineering (ICRAAE), Coimbatore, 2017, pp. 1-5

6. Krishnamoorthy R, Priya S, Aswini LS, Guna C, "Design and Implementation of loT based Energy Management System with Data Acquisition," 2020 7th International Conference on Smart Structures and Systems (ICSSS), Chennai, India, 2020, pp. 1-5, doi: 10.1109/ICSSS49621.2020.9201997

7. Khan I, Ali T, Devanagavi GD, KR, S. and Biradar RC (2018) A Multiband Slot Antenna loaded with Stubs for WLAN/WiMAX/Satellite TV Applications. Advanced Electromagnetics 7(5):74-81

8. Amrutha G, Sudha T, "Triple Band Antenna for 5G Applications," 2018 International Conference on Advances in Computing, Communications and Informatics (ICACCI), Bangalore, 2018, pp.1650-1652

9. Sanil N, Venkat PAN, Ahmed MR, "Design and Performance Analysis of Multiband Microstrip Antennas for loT applications via Satellite Communication," 2018 Second International Conference 
on Green Computing and Internet of Things (ICGCloT), Bangalore, India, 2018, pp. 60-63

10. Yan S, Soh PJ, Vandenbosch (2014) Low-profile dual-band textile antenna with artificial magnetic conductor plane. IEEE Trans Antennas Propagation 62(12):6487-6490

11. Lin DB, Chou JH, Fu SO, Li HJ, "A compact dual-band printed antenna design for LTE operation in handheld device applications," International Journal of Antennas and Propagation, 1-9, 2014

12. Akpakwu G, Anuga et al (2017) "A survey on $5 G$ networks for the Internet of Things: Communication technologies and challenges". IEEE Access 6:3619-3647

13. Sohail A, Khan H, Khan U, Khattak MI, Saleem N, Nasir JA, "Design and Analysis of a Novel Patch Antenna Array for 5G and Millimeter Wave Applications," 2019 2nd International Conference on Computing, Mathematics and Engineering Technologies (iCoMET), Sukkur, Pakistan, 2019, pp. 1-6

14. Prahlad N, Sanil PA, Naga Venkat, Ahmed MR, "Design of an U shaped slotted patch antenna for RFID Vehicle Identification," 2018 Second International Conference on Green Computing and Internet of Things (ICGCloT), Bangalore, India, 2018, pp. 300-304

15. P. M, R. V and Ahmed MR, "Multiband Circularly Polarized Microstrip Reader Antenna for RFID Applications," 2018 Second International Conference on Green Computing and Internet of Things (ICGCloT), Bangalore, India, 2018, pp. 64-67

16. Verma S, Mahajan L, Kumar R, Saini HS, Kumar N, "A small microstrip patch antenna for future $5 \mathrm{~g}$ applications," in Reliability, Infocom Technologies and Optimization (Trends and Future Directions) (ICRITO), 2016 5th International Conference on. IEEE, 2016, pp. 460-463

17. Iqbal A, Sani FR, Ullah Z, Khattak MI, Khattak MA, Saqib N, Masood H, "Comparative study of micro strip patch antenna for $x$ band using micro strip line feed and coaxial feed," in Engineering and Emerging Technologies (ICEET), 2018 International Conference on. IEEE, 2018, pp. 1-6

18. Rajeev Dandotia R, Mishra SM, Bhaskar RG, Mishra, Piyush Kuchhal, SSR Based Slotted Patch Antenna with Integrated Wave Guiding structure for $5 \mathrm{G}$ Application, International Journal of Engineering and Advanced Technology (IJEAT), vol-9 Issue-2, pp 3950-3955, December, 2019

19. Anbuchezhian N, Velmurugan T, Suganya Priyadharshini T, Krishnamoorthy R, Novel Design of Hybrid Steam Turbine Reflector Based Controller for Solar Power Plant, https://doi.org/10.15866/ ireme.v14i9.19510, vol 14, N 9 pp. 572-578, 2020

20. Ranjan Mishra RG, Mishra P, Kuchhal, Analytical Study on the Effect of Dimension and Position of Slot for the Designing of Ultra Wide Band (UWB) Microstrip Antenna, Intl. Conference on Advances in Computing, Communications and Informatics, pp 502-507, 2016

21. Fitri, Akbar TAA, "A new gridded parasitic patch stacked microstrip antenna for enhanced wide bandwidth in $60 \mathrm{GHz}$ Band," 2017 International Conference on Broadband Communication, Wireless Sensors and Powering (BCWSP), Jakarta, 2017, pp. 1-4

22. Jilani SF, Alomainy A, "A Multiband Millimeter-Wave 2-D Array Based on Enhanced Franklin Antenna for $5 \mathrm{G}$ Wireless Systems," in IEEE Antennas and Wireless Propagation Letters, vol. 16, pp. 29832986,2017 
23. Sun H, Zhang Z, Hu RQ, Qian YWearable (2018) Communications in 5G: Challenges and Enabling Technologies. IEEE Veh Technol Mag 13:100-109

24. Baker SB, Xiang W, Atkinson I (2017) Internet of Things for Smart Healthcare: Technologies, Challenges, and Opportunities. IEEE Access 5:26521-26544

25. Hu JR, Li JS, Wu D, “A small planar antenna for $4 G$ mobile phone application," International Journal of Antennas and Propagation, 1-7, 2016

26. Cihangir A, Panagamuwa CJ, Whittow WG, Jacquemod G, Gianesello F, Pilard R, Luxey C (2017) Dual-band $4 \mathrm{G}$ eyewear antenna and SAR implications. IEEE Trans Antennas Propagation 65(4):2085-2089

27. Zhang S, Li Y, Tian Q, Liu L, Yao W, Chi C, Zeng P, Zhang N, Wu W (2018) Highly conductive, flexible and stretchable conductors based on fractal silver nanostructures. J Mater Chem C 6:3999-4006

28. Kim N, Lienemann S, Petsagkourakis I, Mengistie DA, Kee S, Ederth T, Gueskine V, Leclère P, Lazzaroni $\mathrm{R}$, Crispin $\mathrm{X}$ et al (2020) Elastic conducting polymer composites in thermoelectric modulesNat Commun 11:1-10

\section{Figures}
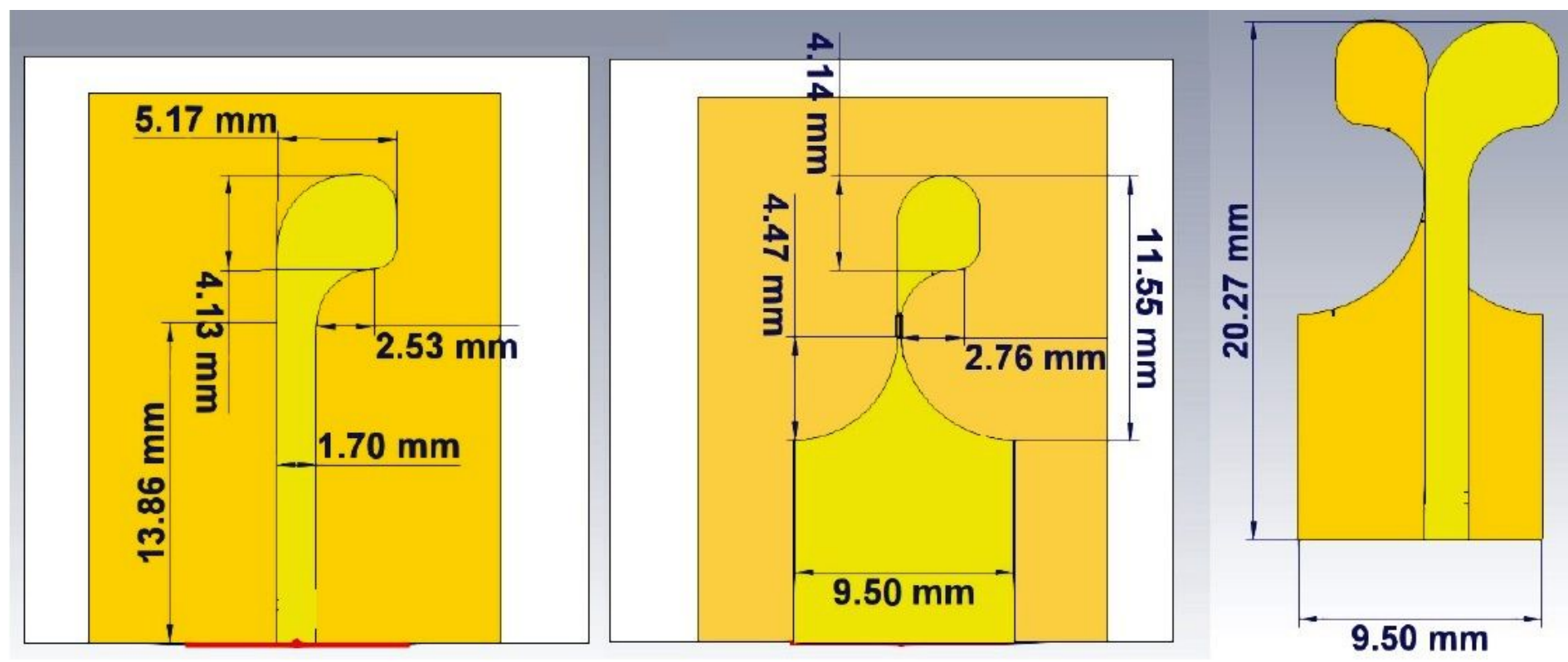

Figure 1

Proposed Antenna's Design (a) Top View (b) Bottom view (c) Antipodal type Alignment on Either Sides 


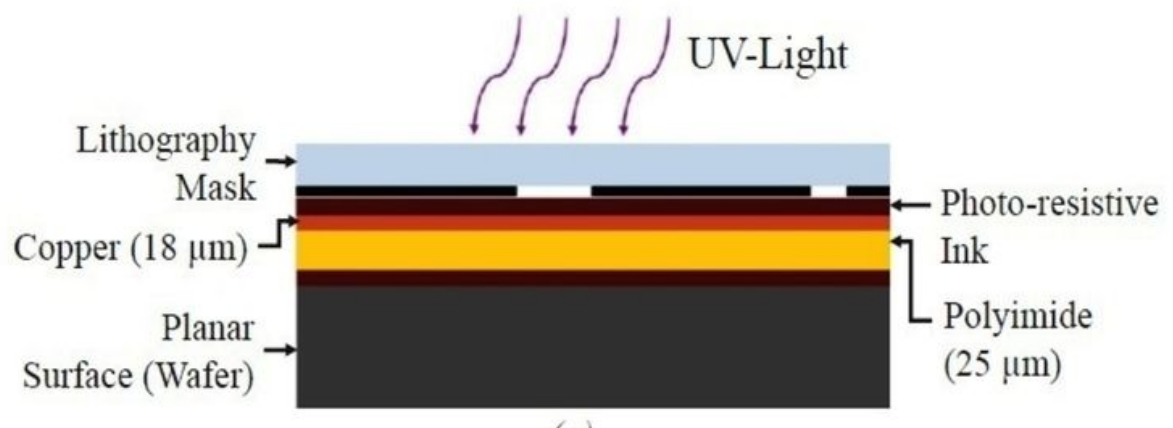

(a)

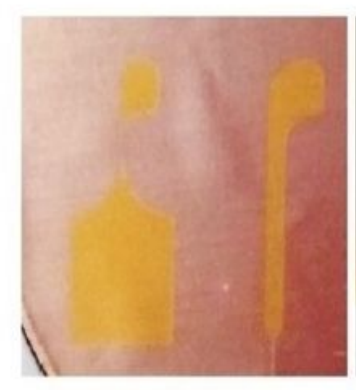

(e)

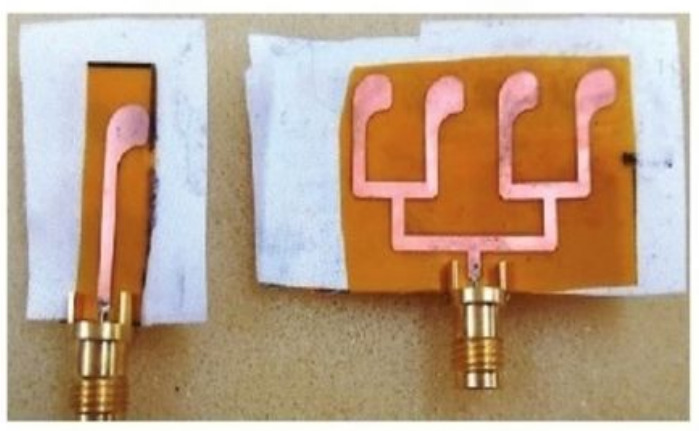

(g)

Figure 2

Fabrication of Proposed Antenna (a) C.S during Process of UV exposure (b \& c) C.S Before and After Etching (d) Structure Assembly on Textile (e) Top View before Etching (f) Top View after Etching (g) Test Connector $1.85 \mathrm{~mm}$ with single element and an Array of $4 \times 1$

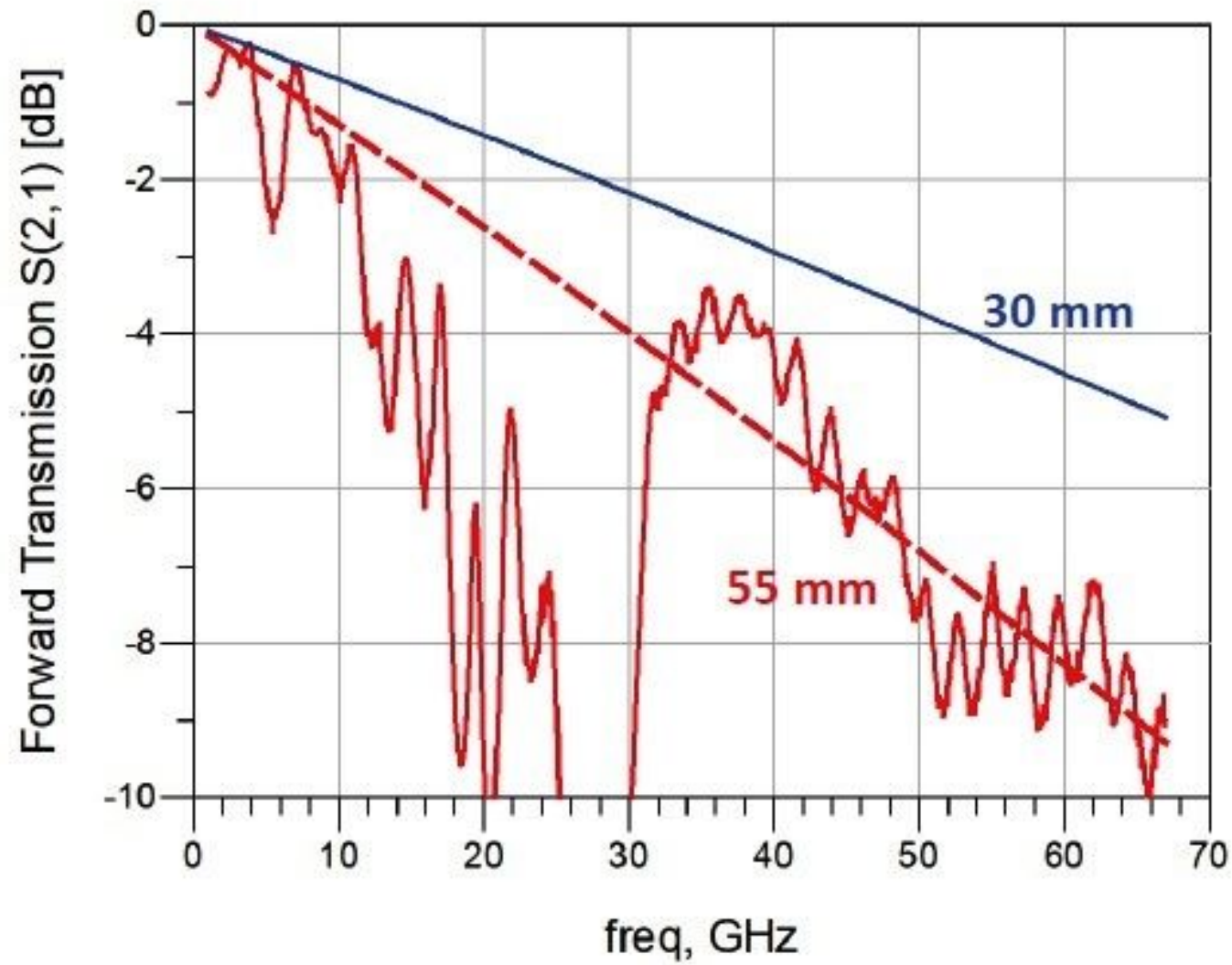


Figure 3

Insertion Loss due to $30 \mathrm{~mm} \& 55 \mathrm{~mm}$ Microstrip line

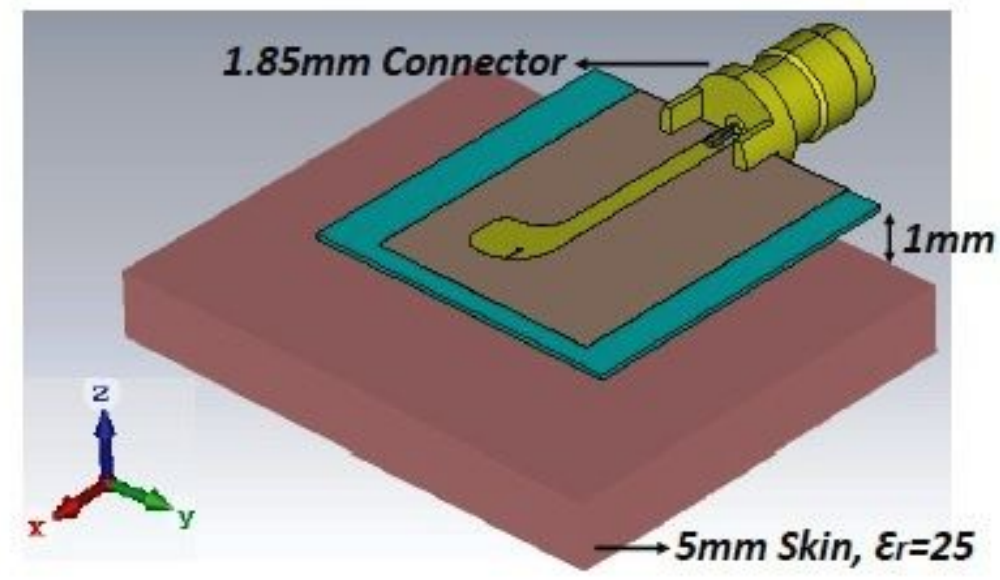

Figure 4

CST Based 3D Model of Proposed Antenna

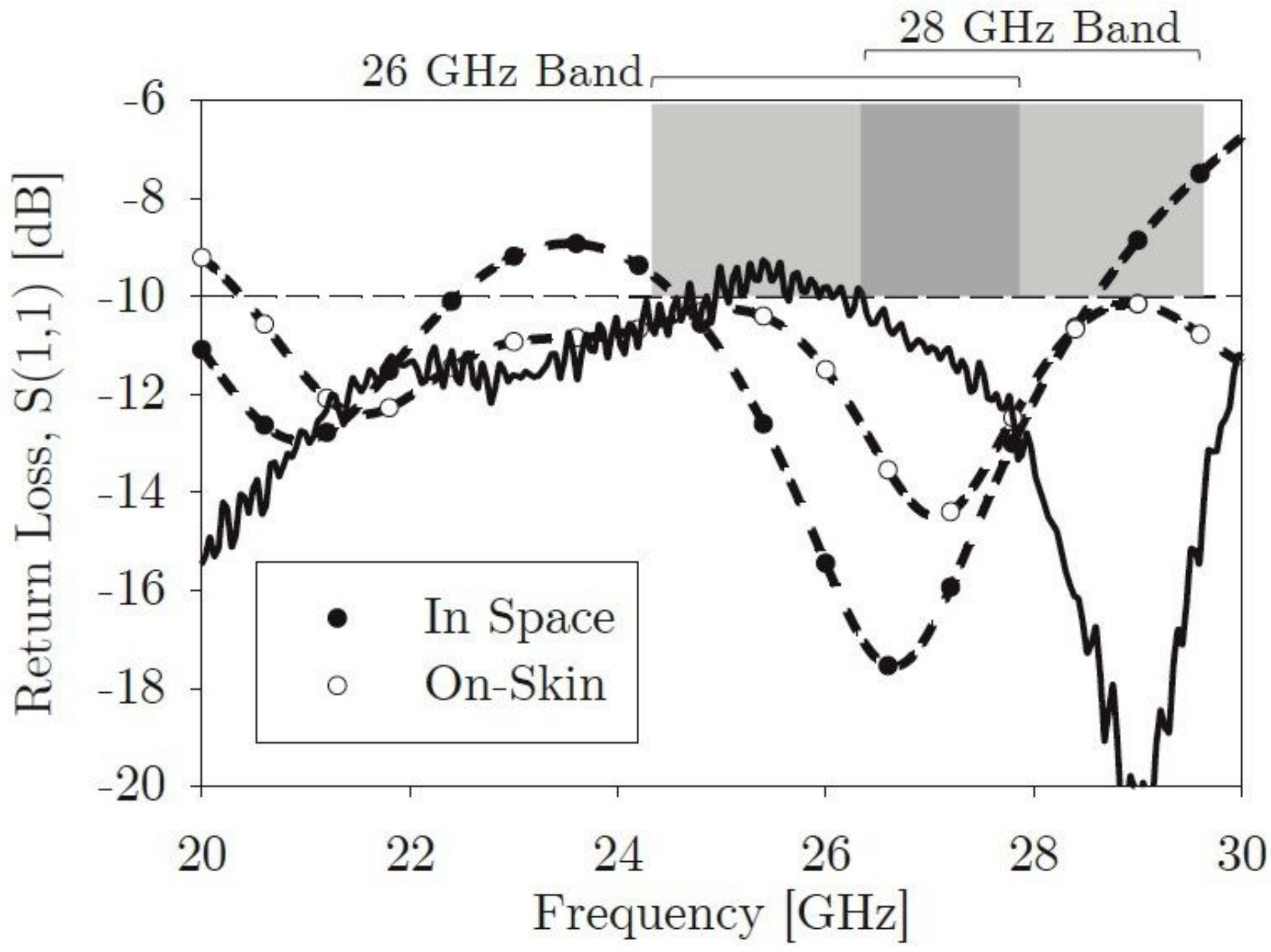


Figure 5

Return Loss of Antenna in Space \& on Skin
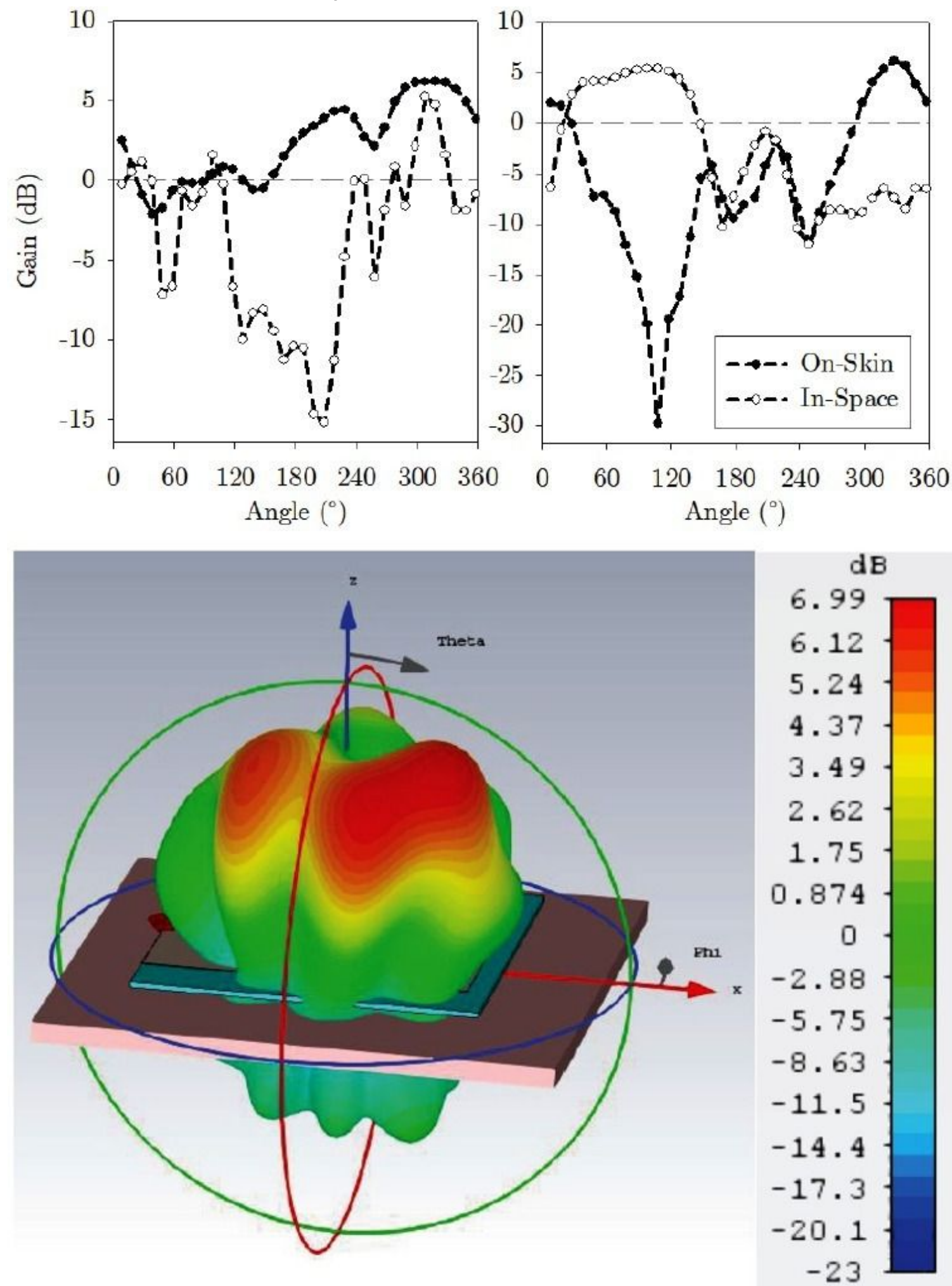

Figure 6

Radiation plot of Antenna in Cartesian Parameters at $28 \mathrm{GHz}$ (a) E-Plane (b) H-Plane (c) 3 D Radiation Plot of Proposed Antenna Design at $28 \mathrm{GHz}$ 


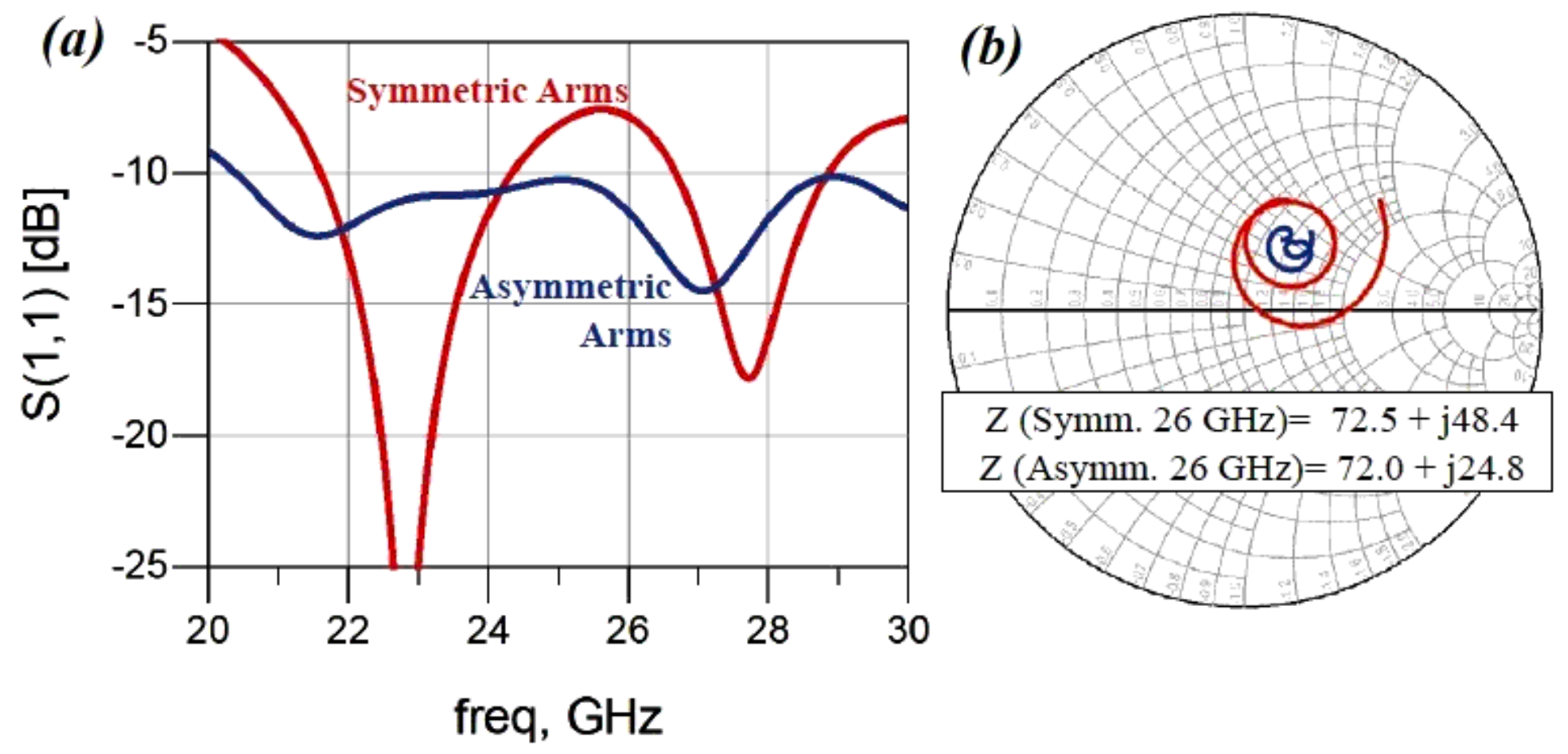

Figure 7

a) \& (b) Simulated S11 Parameter of Proposed Antenna at $26 \mathrm{GHz}$

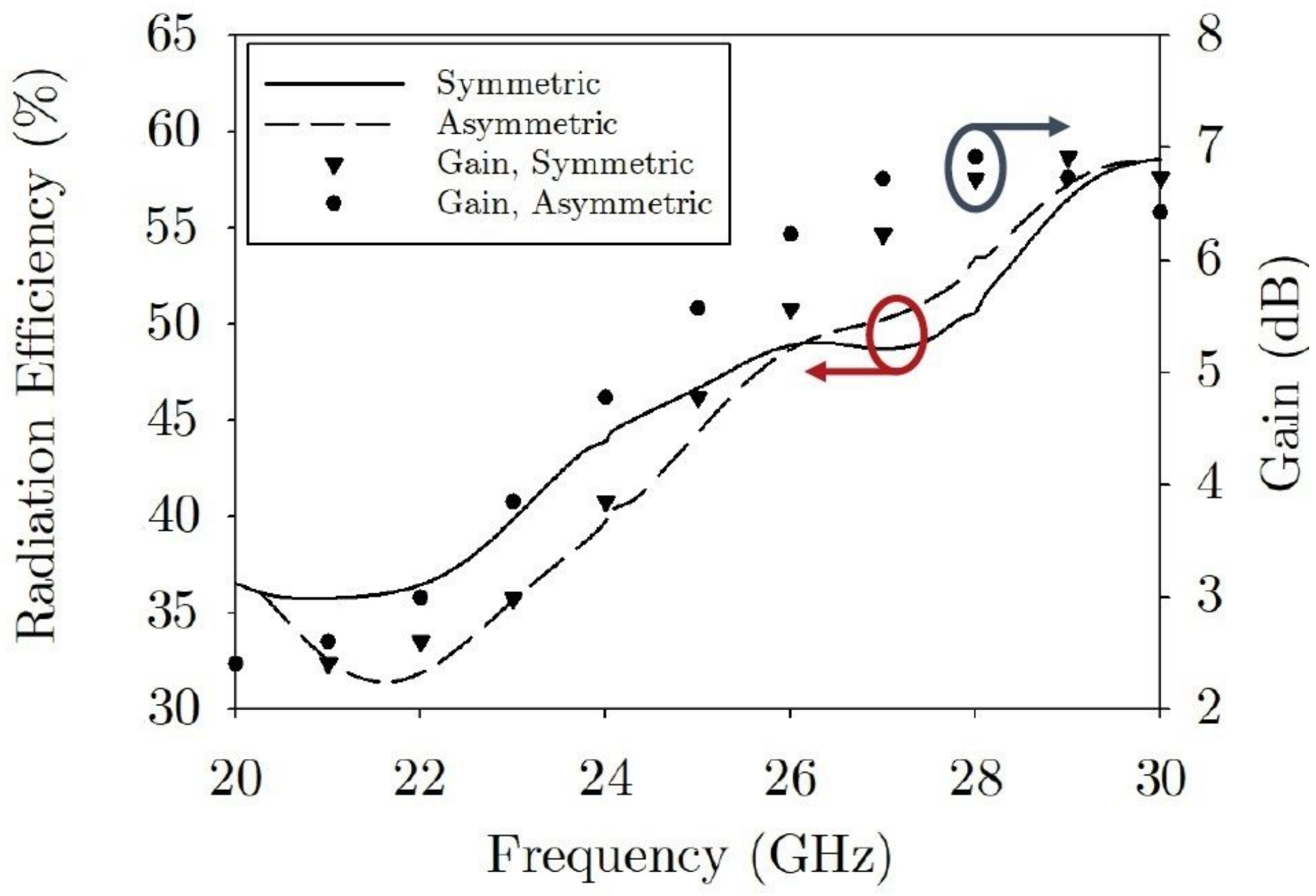


Figure 8

Simulation of Radiation Efficiency and Antenna Gain for Symmetric \& Asymmetric arm Placement 